\title{
HIGHLY EFFICIENT TECHNOLOGY \\ FOR MANUFACTURING OF SPUNLACE \\ sciendo NON-WOVEN FABRIC IN THE COMPANY NOVITA \\ S.A. POLAND - DESCRIPTION \\ AND CHARACTERISTIC OF THE R\&D ACTIONS
}

doi:10.2478/mape-2018-0034

Date of submission of the article to the Editor: 03/2018

Date of acceptance of the article by the Editor: 06/2018

MAPE 2018, volume 1, issue 1, pp. 269-277

\author{
Michał Sąsiadek \\ Waldemar Woźniak \\ Bartłomiej Jankowski \\ Urszula Błaszczyk \\ University of Zielona Gora, Poland \\ Roman Stryjski \\ Novita S.A. Zielona Gora, Poland
}

\begin{abstract}
This paper presents the process of designing Research and Development actions for innovative technology of highly efficient manufacturing of Spunlace non-woven fabric with the use of the designed demonstrative technological line. Both the designing of the technological line and the research are response to the market needs of the personal care products manufacturers in Poland and in the world. Clients' expectations concerning this matter deal with increasing the production volume as well as providing better quality of the products. Due to limited (and fully exploited) production capacities and already-known technical problems in the enterprise where the research has been carried out, the authors designed a concept of innovative controlling of the technological line gradually increasing its efficiency. In order to do so, the authors proposed research based on designing the technological line mathematical model, creating its prototype and testing its operational capacities, saving the data in the database and then the use of this empirical data to the technological line parametrisation depending on the properties and destination of the manufactured products.
\end{abstract}

Keywords: spunlace non-woven fabric, manufacturing, technological line research project

\section{INTRODUCTION}

Commercialisation of the carried out research results is a significant impulse to implement changes in the economic process. The search of new products, new consumer markets, new applications or new technologies is undoubtedly a challenge for research and development (R\&D) departments of economic entities. The idea of commercialisation begins most often with developing the concept of a new technology or a new product, then moves on to carrying out research actions over the new solution and finishes with all the marketing operations allowing introducing the product into the market. There are various research results of commercialisation models presented in the subject area literature which show some similarities with regard to repeating action groups. Such examples may be the models proposed by (Jolly, 1997), (Schumpeter, 1964) and (Cooper et al., 1998), where the segmentation approach to research commercialisation is clearly visible. The research process initiation is begun with an idea or a discovery and is finished with commercialisation and introducing the new solutions into the market (Javed et al., 2017).

The whole process is highly time and cost consuming which results in discouraging the enterprises from investing in scientific research and searching for innovative solutions. A 
different view is proposed by TRL (Technology Readiness Levels) model definied and described by (Shishkio et al., 2003) and (www.nasa.gov, 2010, 2012) which simplifies and shortens time of the research commercialisation by, among others, assessment of new technologies maturity.

This assessment allows even for the actions on new product or technology development, analyses further development opportunities, estimates the amount of financial resources necessary for the investment as well as assumes and calculates the innovation risk (Peters, 2015). Therefore, the assessment becomes a source of information and a tool supporting the decision making process. In the TRL model (fig. 1) it is called "Technology Readiness Assessment" (TRA) (Sauser et al., 2006) and (Lavoie and Daim, 2017).

Due to dynamic changes on the textile market as well as familiarity of existing non-woven fabric production technologies, it has been decided to use the TRL model for commercialisation of research activities concerning highly efficient technology for manufacturing of Spunlace non-woven fabric.

\section{TECHNOLOGY READINESS LEVELS}

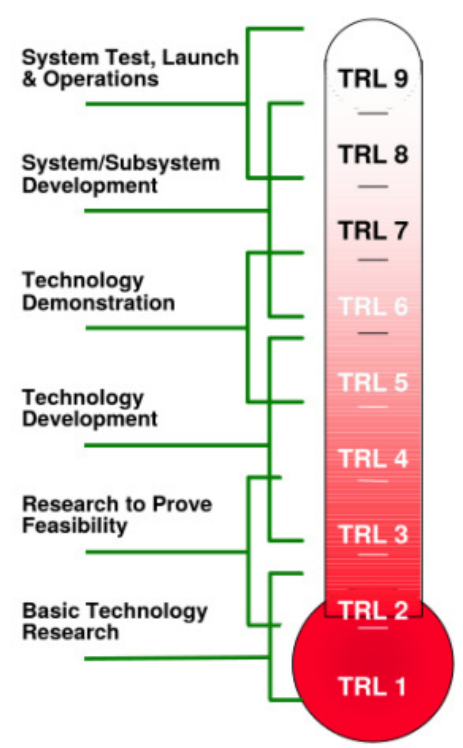

Actual system "flight proven" through successful mission operations

Actual system completed and "flight qualified" through test and demonstration (Ground or Flight)

System prototype demonstration in a space environment

System/subsystem model or prototype demonstration in a relevant environment (Ground or Space)

Component and/or breadboard validation in relevant environment

Component and/or breadboard validation in laboratory environment

Analytical and experimental critical function and/or characteristic proof-of-concept

Technology concept and/or application formulated

Basic principles observed and reported

Fig. 1. Technology Readiness Levels

Source: (www.cheatography.com, 2018).

Because of this, the following tasks leading to the commercialisation of the whole process of implementing the innovation in the form of highly efficient technological line for Spunlace non-woven fabric manufacturing have been defined:

- designing the technological process concept,

- developing the technological process theoretical model,

- performing the technological process computer simulations,

- performing trial production run (with all the necessary tests) with regard to pre-defined process and product parameters,

- providing the tables of optimal setup and control parameters of the technological line machines and devices,

- determining the correlation between the machines and devices setup parameters and analysing their influence on the process course and the final product quality,

- technological process monitoring and controlling. 
Due to long-term experience of the R\&D department staff and the fact that Novita S.A. is one of the leaders in Spunlace non-woven fabric production, basic stages of the TRL model $(1,2$,

3) have been omitted and the research process was started from stage 4.

\section{INDUSTRIAL RESEARCH}

According to the accepted methodology, stages IV and V of the TRL model, specified in chapter 1 , are considered as industrial research. Intensive studies and analyses concerning available technological solutions for Spunlace non-woven fabric production with the possibility of scalability of selected mechanical and quality parameters have been carried out within stage IV. This activity was divided into the following tasks:

1) specification of basic Spunlace product (further referred to as the reference product) parameters (interchangeably: properties), specification of the reference product quality features and specification of assumed technological process mechanical parameters;

2) market analysis of suppliers of comprehensive technological lines and/or particular units and devices for the planned technological process of manufacturing of the reference product and products modified with regard to selected parameters (properties) and quality features;

3) laboratory analyses of the product samples obtained from competitive enterprises for their conformity with the reference product and analysis aiming at improvement of the selected parameters (properties) and quality features of the obtained product with regard to the reference product.

The last stage of the first task was to draft a thorough specification of the reference product, where the following were defined:

a) reference product (interchangeably: non-woven fabric) parameters (properties):

- composition ( $20 \%$ viscose, $80 \%$ polyester),

- fibre linear mass: from 0,9 to 1.7 dtex (arbitrary unit: $1 \mathrm{dtex}=10000 \mathrm{~m}$ of fibre/g),

- coefficient of durability of fibres used for non-woven fabric production, that is Machine Direction fibres (MD) to Cross Direction fibres (CD): $M D / C D<2,8$

- - determined based on standard EN 29073-3 "Textiles; test method for nonwovens; part 3: determination of tensile strength and elongation",

- volumetric mass density: $40 \mathrm{~g} / \mathrm{m}^{2}$.

b) general quality features of the reference product (non-woven fabric):

- lack of foreign-bodies: wooden, metal microelements (visual inspection based on a random sample - statistical method of the obtained reference product),

- lack of hyperchromia (visual inspection based on a random sample - statistical method of the obtained reference product),

- lack of thickening (visual inspection based on a random sample - statistical method of the obtained reference product),

c) mechanical parameters of technological process based on written statements of the manufacturers, especially:

- maintaining the process stability at the speed of the units and devices in the planned technological process of the reference product manufacturing ranging from 250 to 300 meters per minute $(\mathrm{m} / \mathrm{min})$ and the width equalling $3.2 \mathrm{~m}$ that is reaching the efficiency of 2 tonnes per hour $(\mathrm{T} / \mathrm{h})$,

- maintaining the process stability in the production regime of 365 days and 24 hours a day with the OEE coefficient $=85 \%$ (OEE - Overall Equipment Effectiveness) (Stecuła and Brodny, 2016).

The next task consisted of a market research with regard to manufacturers and suppliers of machines and devices for the planned technological process. Business contacts with the world's most famous manufacturers and suppliers of devices for Spunlace non-woven fabric production were established. It turned out during the analysis that there are no 
manufacturers and suppliers of comprehensive solutions for production of the planned reference product. Therefore, industrial research was limited only to the manufacturers of critical devices in the designed technological line such as carding machines and needle punching machines/needle looms (practically 3 suppliers worldwide).

Based on the materials and technical specifications obtained from the leading manufacturers it was concluded that the assumed parameters within the area of the technological process as well as the reference product are possible to achieve. They were preliminary assumptions due to the fact that the technical parameters had to be considered individually based on the performance of particular and independent devices instead of the whole designed technological line as it had been expected. This resulted in designing of an innovative technological solution by the authors which consists of independent devices supplied by different manufacturers that will guarantee mass production of the reference product. Therefore, the methodology of research activities based on theoretical modelling and simulations and then designing, prototype construction, testing and launching of the planned technological process was adopted.

The third task was limited to tests of materials and quality of the non-woven fabric samples having specified features and properties of the reference product. The samples were obtained from the Spunlace non-woven fabric manufacturers who were chosen by the manufacturers and suppliers of devices required for the planned technological process. Even though the non-woven fabric samples complied to the assumed reference product, none of the suppliers (while carrying out of the industrial research by Novita S.A.) confirmed that the reference product had been manufactured according to assumed mechanical parameters of the technological process.

In the next part of the industrial research carried out (TRL V), within two months Novita S.A. $R \& D$ team analysed the mechanical parameters as well as operational and maintenance manual of the planned technological process. In order to do so, the R\&D team visited the largest manufacturers and suppliers of the devices (especially carding machines and needle punching machines) for Spunlace non-woven fabric production in the world. Unfortunately, none of the manufacturers was able to present a complete technological process for Spunlace non-woven fabric production according to accepted mechanical parameters of the process. All the trials dealt exclusively with selected actions in the process performed by the tested devices and semi-finished products provided by these devices.

On the basis of the obtained semi-finished products (e.g. spunlace after carding), it was impossible to unequivocally define the parameters and quality features of the final reference product. Furthermore, due to short time of the presented trial, the R\&D team was unable to evaluate the process stability (emergency stops) and its efficiency. Therefore, reassurement and guarantees of the above mentioned manufacturers and suppliers remained only in the sphere of theory without any possibility of verifying them in the environment close to realexisting conditions.

Industrial research carried out by Novita S.A. confirmed that the planned technological process is theoretically possible to be implemented (based on the obtained documentation, visits in the enterprises manufacturing particular units and devices as well as the product samples obtained by the suppliers mentioned above). On the basis of this research, it was stated that the condition enabling the achievement of the assumed parameters of the reference product and technological process is carrying out of the research and development operation based on:

- modelling and simulations of technological process of Spunlace non-woven fabric production in order to properly select and adjust the units and devices;

- prototype construction, trial production run, data collection and its analysis in order to optimise the parameters of technological process of Spunlace non-woven fabric production; 
- verifying the stability/failure rate of technological process of Spunlace non-woven fabric production with the assumed efficiency.

Unfortunately, this data could not be obtained neither from the manufacturers and suppliers of the units and devices (due to lack of proper tests), nor from the competition (due to business secret/trade secret)

\section{RESEARCH ACTIONS}

As a result of the industrial research and obtained conclusions, Novita S.A. decided to implement the project and construct the prototype of the technological line for highly efficient manufacturing of Spunlace non-woven fabric according to the parameters of the accepted reference product.

On the basis of the methodology of carrying out research and development action (stage VI of TRL), it was planned to create a mathematical model together with its testing with the use of a computer simulation of technological process of Spunlace non-woven fabric manufacturing. The aim of this part of the project will be a detailed specification of the technological process consisting of various independent units of machines and devices for the reference product manufacturing and its scalability, that is changing the non-woven fabric weight and differentiating the percentage composition of its components - viscose and polyester. It is assumed that the basic research parameter for the whole process composed of various machines and devices will be the speed of the ready product coil. It is accepted that the research task will be to adapt the operation of all the machines and devices configured in the technological process in such a way that the process of coiling of $3.2 \mathrm{~m}$ wide non-woven fabric will be conducted effectively at the speed ranging from 250 to 300 $\mathrm{m} / \mathrm{min}$ maintaining at the same time the quality parameters defined by the recipients of the non-woven fabric produced. (during the industrial research it was concluded there is actually no reliable confirmation that any manufacturer produces non-woven fabric of the parameters specified for the reference product and with the proposed setup of technological line in the continuous process with the efficiency of the line as a complete system of above $80 \%$ ).

The problem with such a defined research area will be related to the fact that for each of the machines (unit of devices) present in the designed technological process, there will be specified different parameters influencing the process speed, that is transport and processing of the fibres provided by the feeder, whose consequence will be the obtainment of the proper quality of the final product. It is assumed in the research process that the set speed of needle-punching in the designed "pull" production system will be determining the other setup of all the machines and devices operating in the considered technological process.

The designed model of technological process of non-woven fabric production (with the reference product defined and the process efficiency and quality parameters assumed) will be limited to the set of properly configured machines and devices operating in the technological process as well as their mutual correlation in order to provide real/actual coupling between them (in terms of material and control signals flow). It is planned to create a mathematical model on this basis, thanks to which a simulation reflecting the actual state of technological process will be carried out. Therefore, based on the process simulations, there will be defined theoretical dependencies of particular parameters of the machines and devices (both setup and especially controlling ones) on the defined final process effects.

A dedicated simulation IT tool such as Technomatix Plant Simulation, Enterprice Dynamics or other software available on the market will be used for the technological process modelling and simulation stage.

For computer simulation, the authors defined all the units of machines and devices responsible for the realisation of specified technological operations in Spunlace non-woven 
fabric manufacturing process and their setup options influencing pre-defined key parameters of the technological process, especially:

- Feeding unit, that is weighing and mixing the non-woven fabrics, for which the research parameters will be the fibre (viscose and polyester) weight selection, efficiency of the feeding system with regard to the fibres weight, selection of efficiency parameters of the fans responsible for the fibre mixture transport;

- Carding machine units for which the research parameter will be the speed of the needle punching machines and the quality of the obtained fleece (density and orientation of fibre sets);

- Needle punching machine/needle loom for which the research parameter will be proper selection of water pressure, speed of the elements transporting non-woven fabrics in order to obtain proper density of the fabrics, proper weight and resistance and selection of operation parameters of the fans for creating underpressure to suck off the water after the needle punching process;

- Dryer for which the research parameter will be the choice of optimal temperature and exhaust/suction fan operation parameters due to the possibility of the non-woven fabric burning, over-drying or under-drying;

- Coiler for which the basic research parameter will be the speed of coiling defined in the research process within the range of $250-300 \mathrm{~m} / \mathrm{min}$, which determines the operation parameters of the preceding machine units.

On the basis of this analysis, the $R \& D$ team will prepare a research programme related to:

- defining of physical quantities (allowing for proper units of measurement), their tolerance and the range of changes influencing continuity and stability of the designed technological process,

- creating theoretical model of the technological process by mathematical notation of the parameters defining the physical quantities mentioned above,

- studying the correlation of changes and mutual influence of particular physical quantities with the use of operational research methods,

- uploading the accepted model to the selected simulator and carrying out of the tests with the use of the IT tools enabling defining the range of changes and mutual influence of particular research parameters (that is pre-selected parameters of the technological process) characterising the defined physical quantity,

- collecting data, analysing the results and proposing setup of the tested parameters for various variants of the accepted technological process model.

As a result of the planned research, the R\&D team is expected to create a database containing parameters with their setup range for particular units and devices of the technological process and theoretically allowing the speed of coiling the non-woven fabric within the range of 250 to $300 \mathrm{~m} / \mathrm{min}$ with the width of $3.2 \mathrm{~m}$ for the reference product and for products with the variable fibre proportion, variable fibre linear mass, variable MD/CD coefficient but not higher than 2.8 and variable volumetric mass density.

Designing a remote system for monitoring the working parameters of particular elements of the technological process will be an additional effect of this stage of the research.

Construction of the prototype of technological line for highly efficient Spunlace non-woven fabric manufacturing and performing its trial production run are planned in the next stage of the research, according to the accepted methodology of carrying out the research actions ( 7 stage of the TRL). The aim of this stage will be to check the compatibility of the developed mechanical parameters of the designed technological line (that is setup parameters registered in the database on the basis of theoretical analyses and simulations: stage $\mathrm{VI}$ of the TRL) in the operating conditions.

All the mechanical parameters concerning particular units of devices as well as the whole technological process are assumed to be verified at this research stage. Particular attention 
is going to be drawn to measuring the speed and parameters influencing speed at particular units of devices in the process connected with the transport of processed fibres and Spunlace non-woven fabric production. Furthermore, in order to optimise the technological process operating parameters, it is planned to measure its reliability with regard to the following parameters:

- stability of the process deriving from synchronisation of operation of all the units of devices in the process (measuring time of slowing down or stopping the process),

- uniformity of the process deriving from uniform load of the devices operating in the parallel system, e.g. fibre mixing operation (checking the quality of the mixed fibres by visual inspection),

- durability of the product deriving from measuring the MD/CD coefficient which should not be higher than 2.8 for the speed ranging from 250 to $300 \mathrm{~m} / \mathrm{min}$ with maintaining the highest possible speed. It is assumed that the needle punching operation and setup of technological water pressure hitting the transported non-woven fabric resulting from this operation will have the greatest influence on this coefficient (testing the stress of the ready-made non-woven fabric),

- quality of the process deriving from the speed of finding the pollutants caused by the feed material, that is, among others, quality of the BIGBAGs with viscose and polyester (checking the material waste due to occurrence of pollutants).

The most important threats, which may constitute a technological barrier to highly efficient manufacturing of Spunlace non-woven fabric, will be defined at this stage. The most important threat may be disturbances and emergency stops of the technological line due to its unusual speed. It has been calculated that every stop of the process and technological material waste related to this means losses of about 3500 Euro (it is assumed that the designed technological line will be processing 2.5 tonnes of raw material per hour in the process of the reference product manufacturing, which is equal to about 3500 Euro). This calculation however, does not allow for the other costs constituting the general company costs and costs for maintaining and exploiting of the technological line.

The last stage of the planned research (stage 8 according to TRL) will be the final demonstration of the designed technological line allowing for change of the technological parameters obtained during the trial production run (with all the necessary tests) of the prototype of the designed technological line. As a result of the research operations (TRL, stages 6 and 7), the setup database should contain optimal mechanical parameters (coiling speed) and guarantee proper quality parameters (colour, uniform thickness, MD/CD coefficient at the level not higher than 2.8) of the produced non-woven fabric. Because of this it is planned to carry out tests aiming at obtaining uniform quality parameters of the reference product as well as other variants related to the change of the non-woven fabric properties and mechanical parameters of the technological line.

The research process will also include designing of measuring sites, all the required wiring installations and systems in these sites and then data collecting and analysis of selected quality parameters with the use of controlling and measuring solutions available on the market. The following are planned to be used for the research process:

- sensors enabling metal detection for the unit of devices responsible for mixing the fibres (metal residues here result from the fibre quality supplied in the BIGBAGs) and after the needle punching and drying process (metal residues here may result from the pollutants coming from units of devices taking part in the technological process);

- sensors using X-ray sensors for detecting hardening of the processed non-woven fabric deviating from the accepted standard (thickness) on the level of the units of devices responsible for carding and after drying; 
- inspection cameras for checking the non-woven fabric purity after drying (any kind of discolouration which may result from overheating of the non-woven fabric during the drying operating at the speed in the range of $250-300 \mathrm{~m} / \mathrm{min}$ ).

Errors detected and registered by the unit of sensors and cameras will be continuously and permanently analysed in order to change the setup of mechanical parameters of the units of devices in the technological process. This will be a determinant for carrying out further actions aiming at optimisation of the technological process of highly efficient manufacturing of non-woven fabric of mass equalling $40-50 \mathrm{~g} / \mathrm{m} 2$. It means that the optimal ranges of the technological process operation will be empirically determined. These ranges guarantee the obtainment of base mechanical parameters (that is production speed ranging from 250 to $300 \mathrm{~m} / \mathrm{min}$ and width of the non-woven fabric equalling $3.2 \mathrm{~m}$ for various fibre weight, with the MD/CD durability not higher than 2.8) and quality parameters specified by the non-woven fabric recipients (uniform load, uniform thickness and durability of the non-woven fabric) in the straight-line production in continuous regime of 365 days and 24 hours a day with the OEE coefficient $=85 \%$.

\section{SUMMARY}

Demand for the non-woven fabric, which is the subject of this paper, has been dynamically increasing over the last years and forecasts and predictions for the coming years are also promising, especially in the context of new, emerging markets, which are African and South American countries. In order to be up to the changing market conditions as well as competence, the company NOVITA S.A. decided to implement an innovative technological line for Spunlace non-woven fabric production. The line and its particular modules are described in this paper. The planned research process and its stages are also thoroughly characterised and specified. It is assumed that thanks to construction of the technological line prototype and carrying out all the planned tests and research the expected effect in the form of - Designing of demonstrative technological line for highly efficient manufacturing of Spunlace non-woven fabric equipped with central control system will be achieved.

Implementation of the characterised technological line in the company NOVITA S.A. will gradually contribute to increasing the company's production capacities and manufacturing of non-woven fabric of quality and quantity properties desired by a very demanding market (personal care).

\section{ACKNOWLEDGEMENTS}

This article was prepared and published in the scope of project of Designing of demonstrative technological line for highly efficient manufacturing of Spunlace nonwoven fabric equipped with central control system No. POIR.01.01.01-00-0179/17-00 financed by the Polish National Center for Research and Development (NCBiR).

\section{REFERENCES}

Cheatography Com. (2008) https://www.cheatography.com/davidpol/cheat-sheets/dod-technologyreadiness-levels/.

Cooper, R.G., Edgett, S.J., Kleinschmidt, E.J. (1998). Best Practices for Managing R\&D Portfolios, Research-Technology Management, (41) 4, pp. 20-33.

Javed, K., Gouriveau, R. and Zerhouni, N. (2017). State of the art and taxonomy of prognostics approaches, trends of prognostics applications and open issues towards maturity at different technology readiness levels. Mechanical Systems and Signal Processing, 94, pp. 214-236.

Jolly, V.J, (1997). Commercializing new technologies: getting from mind to market. Harvard Business School Press, Boston.

Lavoie, J. R. and Daim, T. U. (2017). Technology Readiness Levels Improving R\&D Management: A Grounded Theory Analysis. In: Management of Engineering and Technology. Portland International Conference on. IEEE, pp. 1-9.

Nasa. (2010). https://www.nasa.gov/pdf/458490main_TRL_Definitions.pdf. 
Nasa. (2012). https://www.nasa.gov/directorates/heo/scan/engineering/technology/txt_accordion1.html. Peters, S. (2015). A readiness level model for new manufacturing technologies. Production Engineering, 9(5-6), pp. 647-654.

Sauser B., Ramirez-Marquez J., Verma D., Gove R. (2006). From TRL to SRL. In: The Concept of Systems Readiness Levels Conference on Systems Engineering Research. Los Angeles.

Schumpeter, J. A., Business Cycles. (1964). A Theoretical, Historical and Statistical Analysis of the Capitalist Process. New York: McGraw Hill.

Shishkio, R., D.H. Ebbeler, and G. Fox. (2003). Nasa Technology Assessment Using Real Options Valuation. Systems Engineering 7(1), pp.1-12.

Stecuła, K., Brodny, J. (2016). Application of the OEE model to analyze the availability of the mining armored face conveyor. SGEM 2016 Conference Proceedings, Book1 Vol. 2, pp. 57-64. 